\title{
Additional probiotic therapy lowers SCORAD index in children with atopic dermatitis
}

\author{
Jessica Ekaputri*, Rita Evalina*, and Melda Deliana*
}

\begin{abstract}
Division of Allergy Immunology, Department of Pediatrics, Faculty of Medicine,

University of Sumatera Utara, Medan

Correspondence :

dr. Jessica Ekaputri

Division of Allergy Immunology,

Department of Paediatrics,

Faculty of Medicine,

\section{BACKGROUND}

Atopic dermatitis (AD) is a common skin disease that is usually chronic, relapsing, causing pruritus and frequent in children. The pathogenesis of $\mathrm{AD}$ involves genetic, immunological and environmental factors causing skin barrier dysfunction and dysregulation of the immune system. Probiotic treatment has been claimed to offer several functional properties including stimulation of the immune system and plays an important role in AD. The objective of this study was to evaluate the effect of probiotic therapy on atopic dermatitis in children.
\end{abstract}

University of Sumatera Utara,

Jl. Dr. Mansyur No. 5 Medan,

Sumatera Utara 20155.

Email: jessicaekaputri58@gmail.com

Univ Med 2016;35:68-74

DOI: 10.18051/UnivMed.2016.v35.68-74 pISSN: 1907-3062 / eISSN: 2407-2230

This open access article is distributed under a Creative Commons Attribution-Non Commercial-Share Alike 4.0 International License

\section{METHODS}

A randomized controlled trial was conducted on 62 children suffering from AD from December 2015 to January 2016. AD severity was assessed based on the scoring of atopic dermatitis (SCORAD) index. Subjects were divided into two groups consisting of 32 and 30 children, the probiotic (probiotic + emollient) and control (emollient) groups, respectively. SCORAD index was re-evaluated after 2 weeks of therapy. The data was analyzed using Mann Whitney test.

\section{RESULTS}

After the intervention, the mean SCORAD index in the probiotic group was significantly much lower than the control group $(18.09 \pm 8.59$ vs $23.21 \pm 8.71 ; \mathrm{p}=0.001)$. The mean decrease in SCORAD index in the probiotic group was $40.4 \%$, much higher than the control group $25.2 \%$. The number needed to treat (NNT) score of probiotic treatment was 5.3.

\section{CONCLUSION}

The addition of probiotics to conventional therapy effectively lowers SCORAD index by $40.4 \%$ in atopic dermatitis. The impact of probiotics on SCORAD indices is thought to be attained by modification of the immunogenicity of potential allergens.

Keywords: Atopic dermatitis, SCORAD, probiotic, children 


\section{INTRODUCTION}

Atopic dermatitis (AD), or eczema, is a common skin disease that is usually associated with other atopic diseases such as allergic rhinitis and asthma. AD is usually chronic, relapsing, causing pruritus and common in children, usually starting in early childhood. ${ }^{(1-3)}$ AD comprises a broad clinical spectrum of mild to severe agerelated disorders. ${ }^{(4,5)} \mathrm{AD}$ pathogenesis involves genetic, immunological and environmental factors causing skin barrier dysfunction and dysregulation of the immune system. ${ }^{(6)}$

Scoring of AD (SCORAD) is a scoring system that was developed to assess the severity of atopic dermatitis by measuring the extent of the area involved, and the intensity of the subjective symptoms of pruritus and sleep disturbance. ${ }^{(7)} \mathrm{AD}$ requires a holistic assessment and its treatment remains a challenge, because it requires an efficient short-term acute symptom control, without affecting the overall treatment plan that is aimed at long-term stabilization, preventing flare-ups and avoiding the side effects of the treatment. ${ }^{(8.9)}$

A probiotic is an oral supplement or food product that contains viable microorganisms in amounts sufficient to change the microflora of the host and have a potential beneficial effect on health. ${ }^{(10)}$ Supplying probiotics plays a role in the prevention and treatment of allergic disease, but the mechanism underlying the immunomodulatory effects is still uncertain. ${ }^{(1)}$ The meta-analysis by Elazab et al. ${ }^{(12)}$ shows that probiotic therapy in the prenatal period and early life reduces the risk of atopic sensitization and total IgE level in children but does not reduce the risk of asthma. The meta-analysis by Boyle et al. ${ }^{(13)}$ shows the opposite where probiotics have the effect of significantly decreasing the symptoms and severity of AD. Another study showed different results, in that there was no benefit from supplementation with $B$. lactis or L. paracasei in the treatment of eczema, when given as an adjunct to basic topical treatment, and no effect on the progression of allergic disease from age 1 to 3 years. $^{(14)}$
The decrease in SCORAD indices caused by probiotics is thought to occur through modification of immunogenicity of potential allergens. The variable effects of probiotics on allergic diseases is likely influenced by the type of probiotic given, and by environmental and host factors. ${ }^{(15)}$

On the basis of the abovementioned information, the purpose of the study was to evaluate the effect of the probiotic supplements to conventional therapy towards the SCORAD index of children with atopic dermatitis.

\section{METHODS}

\section{Research design}

A randomised controlled trial was conducted on selected pediatric patients with atopic dermatitis at two Posyandu (integrated health care stations) in Medan from December 2015 to January 2016.

\section{Research subjects}

The study population consisted of pediatric patients with atopic dermatitis. The research sample comprised the population that met the inclusion criteria, i.e. children aged 1 month to 5 years who satisfied the Hanifin and Rajka criteria for atopic dermatitis. The exclusion criteria were refusal of the children's parents to provide medication, children with malnutrition and other skin diseases. We used the sample size calculation method for comparing two independent proportions. ${ }^{(16)}$ To calculate the sample size, we used a study by Yesilova et al. ${ }^{(17)}$ who reported a standard deviation of the SCORAD index of 13.4 and 6.1, respectively, in the probiotic therapy group and conventional therapy-only group. The calculated sample size per group was 28 , which was estimated to be adequate to detect a $30 \%$ difference between the two groups using a two-tailed test, an alpha of 0.05 and power of $80 \%$.

\section{Measurements}

Anamnesis, physical examination, and anthropometric measurements were performed, 
including the measurement of height and weight of all research subjects. Height was measured in an upright position without footwear, from the feet to the top of the head using a GEA statue meter and expressed in meters (m). Weight was also measured in an upright position using Camry digital scales, and expressed in kilograms $(\mathrm{kg})$. An assessment of body mass index (BMI) was also carried out, the BMI being expressed in units of $\mathrm{kg} / \mathrm{m}^{2}$. All measurements were carried out at the time of the examination of the subject. The severity of atopic dermatitis of each group was rated based on SCORAD index. SCORAD is a clinical tool used to assess the extent and severity of eczema. Dermatologists may use this tool before and after treatment to determine whether the treatment has been effective.

\section{Intervention}

Patients who met the inclusion criteria were included in the study and were divided into two groups by simple randomization i.e. a group that received a probiotic along with conventional therapy (probiotic group) and a group that received conventional therapy only (control group). The probiotic group was given a probiotic orally, administered twice daily for two weeks along with the conventional therapy such as topical emollients, applied three times daily after bathing. The probiotic was given twice a day in the form of a powder containing a mixture of $L$. acidophilus, B. longum, and S. thermophilus, each in amounts of $1 \times 10^{7} \mathrm{CFU} / \mathrm{g}$. The control group was given conventional therapy such as topical emollients applied three times a day after bathing, for two weeks. The research samples were monitored for two weeks to assess the severity of atopic dermatitis based on SCORAD index after the intervention.

\section{Statistical analysis}

The Kolmogorov-Smirnov normality test was used to assess the normal distribution of the data. The independent t-test was to be used on normally distributed data to establish the differences in SCORAD index between case and control groups before and after intervention, and the differences in the decline of SCORAD indices between the two groups, while for non-normally distributed data the Mann-Whitney test was to be used. The number needed to treat test was used to assess the effectiveness of probiotic therapy. Statistical analysis was performed with the SPSS statistical package for Windows, version 17.0, and a p-value of $<0.05$ was considered statistically significant.

\section{Ethical clearance}

The study protocol was approved by the Health Research Ethical Committee, Faculty of Medicine, University of Sumatera Utara (695/ KOMET/FKUSU/2015). All study subjects signed written informed consent after having been informed about the aims and benefits of the study.

\section{RESULTS}

During the study period, 62 subjects suffering from atopic dermatitis were obtained and divided into two groups. The probiotic group of 32 subjects were given a probiotic along with conventional therapy, while the remaining 30 subjects were only given conventional therapy (control group) (Figure1).

There were no significant differences in gender, mean age, and family history of atopy between the two study groups ( $\mathrm{p}=0.422,0.269$, and 1.000; respectively) at base-line (Table 1). Before the intervention, the mean SCORAD index was $30.33 \pm 12.96$ in the probiotic group and $31.05 \pm 10.54$ in the control group, there being no significant differences between the SCORAD index of the two groups $(\mathrm{p}=0.522)$ (Table 1).

After the intervention, it appears that the mean SCORAD index in the probiotic group was significantly much lower than the control group $(18.09 \pm 8.59$ vs $23.21 \pm 8.71, \mathrm{p}=0.010)$. The mean decrease in SCORAD index in the probiotic group was much more than in the control group $(12.23 \pm 6.46$ vs $7.83 \pm 5.49$, $\mathrm{p}=0.001)$ (Table 2). 


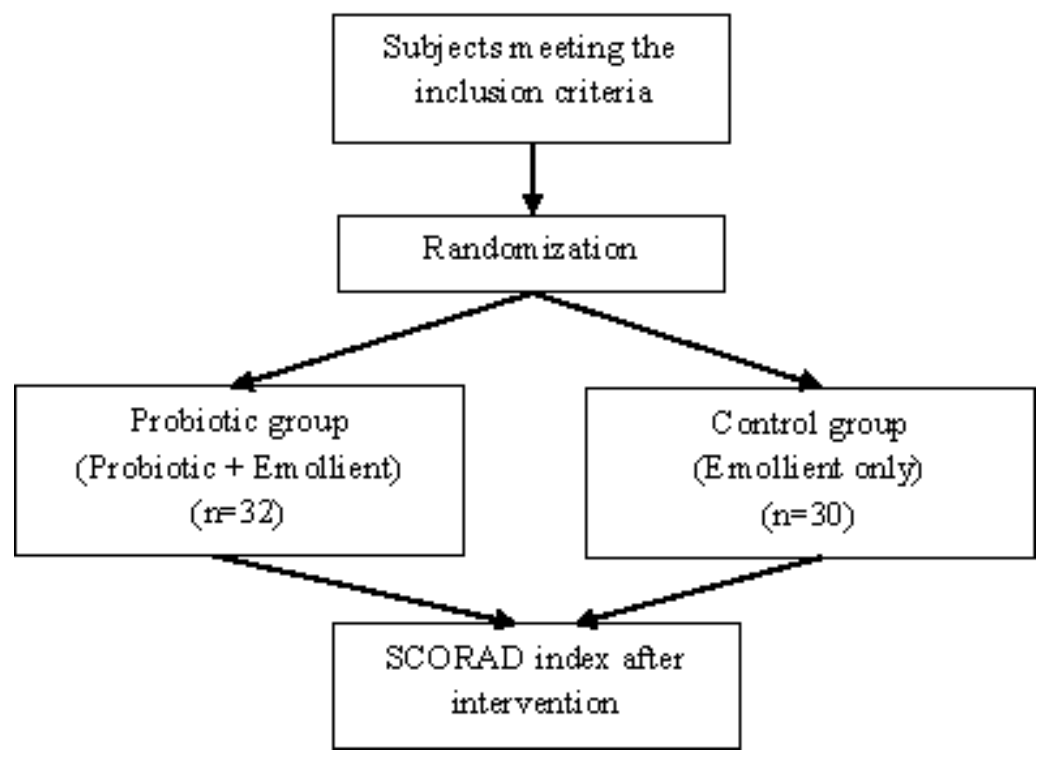

Figure 1. Flow diagram

The number needed to treat was 5.3, meaning that it takes five people to achieve an effect of improvement in the SCORAD values by giving probiotics (Table 3).

\section{DISCUSSION}

The mean age of children with atopic dermatitis was $2.51 \pm 1.59$ years and $2.80 \pm 1.37$ years in the probiotic group and the control group, respectively. Atopic dermatitis is known to be often found during early infancy with an incidence rate of $85 \%$ starting before the age of 5 years. ${ }^{(1.2)}$ In the study no significant differences were found in mean age between the two groups.

After the intervention, there was a significant difference in the mean SCORAD index between the two groups. The above results are similar to those found in the study conducted by Yesilova et al. ${ }^{(17)}$ regarding the administration of a probiotic containing B. bifidum, L. acidophilus, L. casei and $L$. salivarius which showed reductions in SCORAD score and in serum IL-5, IL-6, and IgE levels of atopic dermatitis patients. Likewise, the meta-analytical study by Yao et al. ${ }^{(18)}$ showed significantly lowered SCORAD scores between probiotic and placebo groups. The opposite was found in the meta-analytical study by Boyle et al. ${ }^{(13)}$ in which probiotics did not significantly reduce $\mathrm{AD}$ symptoms compared with placebo. Other meta-analytical studies also found variable probiotic effects in AD. ${ }^{(14,20)}$ Highly heterogenous conditions, including differences in probiotic preparations, study populations and the final results of measurement can directly affect the comparative results of these studies.

Table 1. Demographics and family history of atopy at base-line by treatment group

\begin{tabular}{|c|c|c|c|}
\hline \multirow{2}{*}{ Characteristic } & \multicolumn{2}{|c|}{ Group } & \multirow[b]{2}{*}{$\mathbf{p}$} \\
\hline & Probiotic $(n=32)$ & Control $(n=30)$ & \\
\hline \multicolumn{4}{|l|}{$\operatorname{Sex}, \mathrm{n}(\%)$} \\
\hline Male & $16(50.00)$ & $16(53.30)$ & $0.422^{\star}$ \\
\hline Female & $16(50.00)$ & $14(46.70)$ & \\
\hline Age, mean (SD), years & $2.51 \pm 1.59$ & $2.80 \pm 1.37$ & $0.269^{\mathrm{b}}$ \\
\hline \multicolumn{4}{|l|}{ History of atopy in family, $\mathrm{n}(\%)$} \\
\hline Yes & $30(93.80)$ & $28(93.30)$ & $1.000^{\circ}$ \\
\hline No & $2(6.30)$ & $2(6.70)$ & \\
\hline SCORAD in dex & $30.33(12.96)$ & $31.05(10.54)$ & $0.522^{\mathrm{b}}$ \\
\hline
\end{tabular}

${ }^{\mathrm{a}}$ Chi square test, ${ }^{\mathrm{b}}$ Mann Whitney test, ${ }^{\mathrm{c}}$ Fisher's exact test 
Table 2. Mean differences in SCORAD between groups after two weeks of intervention

\begin{tabular}{lccc}
\hline \multirow{2}{*}{ SCORAD ind ex } & \multicolumn{2}{c}{ Group } & \multirow{2}{*}{ p $^{*}$} \\
\cline { 2 - 4 } & Probiotic (n=32) & Control (n=30) & 0.010 \\
\hline SCORAD index & $18.09 \pm 8.99$ & $23.21 \pm 8.71$ & 0.001 \\
SCORAD index reduction & $12.23 \pm 6.46$ & $7.83 \pm 5.49$ & 0.001 \\
\hline
\end{tabular}

* Mann Whitney test

Previous studies only evaluated the decrease in SCORAD index and other parameters in AD. In the present study, an analysis of the number needed to treat (NNT) was conducted between the two groups and resulted in an NNT of 5.3, which means that it takes five children to get the effect of improving the value of SCORAD. This value indicates that the administration of the probiotic is quite effective as an adjunctive therapy to reduce the severity of atopic dermatitis.

$\mathrm{AD}$ is found among $15-30 \%$ of children and $2-10 \%$ of adults, having increased up to 2 or 3 times in industrialized countries over the past three decades. Atopic dermatitis often begins in early infancy (known as early onset AD). Fortyfive percent of all cases of AD starts in the first 6 months of life, $60 \%$ in the first year and $85 \%$ before the age of 5 years. ${ }^{(1.2)}$

The treatment of AD is intended to overcome itchiness, to repair the skin barrier and to reduce inflammation. The successful treatment of AD relies on a multi-disciplinary approach to education of patients and their families, skin care optimalization, anti-inflammatory medication and treatment of skin infections. ${ }^{(2)}$

The relationship between atopy and the intestinal environment comes from the hypothesis that a deficiency of intestinal microflora in children with atopy will interfere with the required development of the immune response and the normal intestinal mucosal barrier. ${ }^{(21)}$ The microbial intestinal flora or microbiome contributes to the pathogenesis of allergic disease because of its effect on mucosal immunity. Exposure to the normal microbial flora in early life results in the Th-1 / Th-2 lymphocyte balance changing in favor of Th-1 cells. ${ }^{(22)}$

According to the Food and Agriculture Organization (FAO)/World Health Organization (WHO), probiotics are defined as as live microorganisms which when administered in adequate amounts, confer a health benefit on the host. Health benefits have mainly been demonstrated for specific probiotic strains of the following genera: Lactobacillus, Bifidobacterium, Saccharomyces, Enterococcus, Streptococcus, Pediococcus, Leuconostoc, Bacillus, Escherichia coli. ${ }^{(23,24)}$ These microorganisms are fermentative, obligate or facultative anaerobic, usually nonmotile, having different shapes and the majority typically producing lactic acid. ${ }^{(10)}$ The levels of Lactobacillus and Bifidobacterium are significantly decreased in the fecal samples of infants and children with $\mathrm{AD}$, demonstrating the therapeutic potential of probiotic supplementation in AD. ${ }^{(25)}$

There are no specific directions for probiotic dose in atopic dermatitis. Probiotic treatment is more often based on the directions of the probiotic manufacturers. In the present study, the probiotic given twice a day was a mixture of L.acidophilus, B.longum, and S.thermophilus, each to the amount of $1 \times 10^{7} \mathrm{CFU} / \mathrm{g}$. The probiotic was administered for 2 weeks to assess the severity of atopic dermatitis based on SCORAD index.

Table 3. Number needed to treat of probiotic treatment

\begin{tabular}{lccc}
\hline \multirow{2}{*}{ Group } & \multicolumn{2}{c}{ SC ORAD inq rovement } & \multirow{2}{*}{ NNT } \\
\cline { 2 - 3 } & Yes $(\mathbf{n}=\mathbf{2 7})$ & No $(\mathbf{n}=\mathbf{2 9})$ & \multirow{2}{*}{5.3} \\
\hline Probidtic & $19(59.40 \%)$ & $11(36.70 \%)$ & \\
Control & $13(40.60 \%)$ & $19(63.30 \%)$ & \\
\hline
\end{tabular}


This study has limitations which include lack of control and monitoring of patient compliance during the intervention period. Monitoring was only done on the amount of drugs given to the patients, as shown by the fact that no medication was returned by patients during the study.

The results of this study provide new insights into the role of immunologic factors in atopic dermatitis and administration of probiotics can modulate the immune system, thereby improving the symptoms of atopic dermatitis. A broader study is needed to determine the exact mechanisms and the benefits of probiotics in the treatment of atopic dermatitis.

\section{CONCLUSIONS}

The addition of probiotics to conventional therapy effectively lowered the SCORAD index in atopic dermatitis compared to conventional therapy. This result could be a consideration to using probiotics for the treatment of atopic dermatitis. The impact of probiotics on SCORAD indices is thought to be attained by modification of the immunogenicity of potential allergens.

\section{CONFLICT OF INTERESTS}

No conflict of interest to be declared.

\section{ACKNOWLEDGEMENT}

We would like to thank all study subjects who participated in the study, and all colleagues who advised us in writing this report.

\section{REFERENCES}

1. Bieber T. Atopic dermatitis. N Engl J Med 2008;358:1483-94.

2. Watson W, Kapur S. Atopic dermatitis. Allergy Asthma Clin Immunol 2011;7(Suppl 1):S4.

3. Beck LA. Atopic dermatitis. In: Lichtenstein LM, Busse WW, Geha RS, editors. Current therapy in allergy, immunology, and rheumatology. $6^{\text {th }}$ edition. Philadelphia: Elsevier;2004. p.88-92.

4. DaVeiga SP. Epidemiology of atopic dermatitis: a review. Allergy Asthma Proc 2012;33:227-34.
5. Akdis CA, Akdis M, Bieber T, et al. Diagnosis and treatment of atopic dermatitis in children and adults: European Academy of Allergology and Clinical Immunology/ American Academy of Allergy, Asthma and Immunology/ PRACTALL Consensus Report. Allergy 2006; 61:969-87.

6. Eichenfield LF, Tom WL, Chamlin SL, et al. Guidelines of care for the management of atopic dermatitis: Section 1 Diagnosis and assessment of atopic dermatitis. J Am Acad Dermatol 2014; 70:338-51.

7. Charman C, Chambers C, Williams H. Measuring atopic dermatitis severity in randomized controlled clinical trials: what exactly are we measuring? J Invest Dermatol 2003;120:932-41.

8. Darsow U, Wollenberg A, Simon D, et al. Difficult to control atopic dermatitis. WAO J 2013;6:6.

9. Rubel D, Thirumoorthy T, Soebaryo RW, et al. Consensus guidelines for the management of atopic dermatitis: an Asia-Pacific perspective. J Dermatol 2013; 40:160-71.

10. Thomas DW, Greer FR. Committee on nutrition: section on Gastroenterology, Hepatology and Nutrition. Clinical report: Probiotics and prebiotics in pediatrics. Pediatrics 2010;126: 1217-31.

11. Fiocchi A, Burks W, Bahna SL, et al. Clinical use of probiotics in pediatric allergy (CUPPA): a World Allergy Organization position paper. WAOJ 2012;5:148-67.

12. Elazab N, Mendy A, Gasana J, et al. Probiotic administration in early life, atopy, and asthma: a meta-analysis of clinical trials. Pediatrics 2013; 132:e666-e76.

13. Boyle RJ, Bath-Hextall FJ, Leonardi-Bee J, et al. Probiotics for the treatment of eczema: a systematic review. Clin Exp Allergy 2009;39: 1117-27.

14. Gore C, Custovic A, Tannock GW, et al. Treatment and secondary prevention effects of the probiotics Lactobacillus paracasei or Bifidobacterium lactis on early infant eczema: Randomized controlled trial with follow-up until age 3 years. Clin Exp Allergy 2012;42:112-22.

15. Prescott SL, Bjorksten B. Probiotics for the prevention or treatment of allergic diseases. $\mathrm{J}$ Allergy Clin Immunol 2007;120:255-62.

16. Madiyono B, Moechlisan S, Sastroasmoro S, et al. Perkiraan besar sampel. In: Sastroasmoro S, Ismael S, editors. Dasar-dasar metodologi penelitian klinis. $4^{\text {th }}$ edition. Jakarta: Sagung Seto;2011.p.348-381. 
17. Yesilova Y, Calka O, Akdeniz N, et al. Effect of probiotic on the treatment of children with atopic dermatitis. Ann Dermatol 2012;24:189-93.

18. Yao TC, Chang CJ, Hsu YH, et al. Probiotics for allergic disease: realities and myths. Pediatr Allergy Immunol 2010;21:900-19.

19. Lee J, Seto D, Bielory L. Meta-analysis of clinical trials of probiotics for prevention and treatment of pediatric atopic dermatitis. J Allergy Clin Immunol 2008;121:116-21.

20. Michail SK, Stolfi A, Johnson T, et al. Efficacy of probiotics in the treatment of pediatric atopic dermatitis: a meta-analysis of randomized controlled trials. Am Allergy Asthma Immunol 2008;101:508-16.

21. Ogden NS, Bielory L. Probiotics: a complementary approach in the treatment and prevention of pediatric atopic disease. Curr Opin Allergy Clin Immunol 2005;5:179-84.
22. Winkler P, Ghadimi D, Scherezenmeir J, et al Molecular and cellular basis of microflora-host interactions. J Nutr 2007;137:766S-72S.

23. Sekhon BS, Jairath S. Prebiotics, probiotics and synbiotics: an overview. J Pharm Educ Res 2010; 1:13-30.

24. Kaur IP, Kuhad A, Garg A, et al. Probiotics: potential pharmaceutical applications. In: Cho SS, Finocchiaro ET, editors. Handbook of prebiotics and probiotics ingredients. Florida: CRC Press;2010.p.381-408.

25. Pan SJ, Kuo CH, Lam KP, et al. Probiotics and allergy in children: an update review. Pediatr Allergy Immunol 2010;21:e659-e66. 